\title{
Health-Related Productivity Loss: NICE to Recognize Soon, Good to Discuss Now
}

\author{
Wei Zhang • Aslam H. Anis
}

Published online: 18 March 2014

(c) Springer International Publishing Switzerland 2014

The National Institute for Health and Care Excellence (NICE) will soon consider the societal benefit of drugs, including their impact on productivity. Chief Executive Sir Andrew Dillon says NICE was asked by the Department of Health "to take account of wider societal benefit. For example, if we have a condition that significantly reduces our ability to undertake the daily activities that most of us would regard as normal, such as paid employment or caring for children or relatives" [1].

Until now, NICE has upheld that only health sector costs may be incorporated in cost-effectiveness analyses, not the 'indirect' costs such as productivity loss [2, 3]. Numerous reasons were given for this position, e.g., productivity costs were outside the budget purview or incorporating them would discriminate against non-working populations, including the elderly [4]. Critics of NICE retorted that ignoring productivity was tantamount to discrimination against the young, to valuing marginal gains in labor output at zero [4]. Time and again, NICE put these arguments aside. Why the sudden change of heart?

It calls to mind the UK's recent attempt to replace its Pharmaceutical Price Regulation Scheme (PPRS), a voluntary agreement between the Association of the British Pharmaceutical Industry and the government and set to expire in December 2013, by a system of "value-based pricing' (VBP). In light of criticism that the cost-

W. Zhang · A. H. Anis $(\bowtie)$

Centre for Health Evaluation and Outcome Sciences, St Paul's Hospital, 588-1081 Burrard Street, Vancouver, BC V6Z 1Y6,

Canada

e-mail: aslam.anis@ubc.ca

W. Zhang · A. H. Anis

School of Population and Public Health, University of British

Columbia, Vancouver, Canada effectiveness-based threshold set by NICE was too high, VBP was promoted as a new way to link the price of medications to their value to patients and society. Talks around VBP brought together various lobbies, who agreed that VBP should take the 'societal perspective' and account for productivity loss. Although the VBP policy initiative died on the table (the PPRS of old is still in effect [5], albeit with caps on overall pharmaceutical spending growth over the next few years), the beneficiary of this round of politicking is the societal perspective.

This is indeed good news for the welfarists. There are, however, issues around the measurement and valuation of productivity loss that have been given short shrift. Our aim is to highlight some of these issues, as cost-effectiveness studies incorporating productivity are likely to advance quickly in the wake of NICE's decision.

The inclusion of productivity losses in cost-effectiveness analyses has always provoked concerns over measurement and valuation, including problems around double-counting, equity, and perspective [6, 7]. Despite these concerns, decision making will be best informed if studies of new drugs explicitly include all societal costs related to the disease being treated. By clearly presenting all cost components separately alongside methodological assumptions, decision makers will be permitted to assess the impact of different assumptions on the final study results. This has been supported by the recent reporting guideline, Consolidated Health Economic Evaluation Reporting Standards [8, 9].

So what components of productivity loss should be considered? People may lose their paid employment because of their health problems (job loss or early retirement). For people maintaining paid employment, some will reduce their routine work time, or experience periodic absences because of their poor health. While people are 
present at work, their productivity may be reduced because of health problems (presenteeism). Illness also prevents people from unpaid work activities including household work, shopping, childcare, and volunteer work; all of this unpaid work productivity loss should be considered.

In economic evaluations, productivity loss components should be measured first in time (days or hours) and then valued monetarily [7]. Measurement is straightforward for all components except presenteeism. Although over 20 instruments exist, they apply different concepts of presenteeism and serve different purposes (health outcome measurement vs. economic evaluation) [6, 10]. Only some instruments are able to translate presenteeism into time loss, and their estimates vary widely, for example, from 2 to $14 \mathrm{~h}$ over 2 weeks [11]. Thus, the results from studies using different instruments are not comparable and the exact cost amount cannot be determined at this time [12]. The main challenge of presenteeism measurement is the lack of a gold standard or objective measures to test its criterion validity. The objective measures are only available for certain occupations and industries. The criterion validity of existing or newly developed instruments needs to be tested among those occupations and industries. Other productivity measurement issues include recall period, measurement frequency, generic versus disease-specific measures, and measurement methods for unpaid work productivity loss $[6,13]$.

To value productivity loss, two methods are commonly used, the Human Capital (HC) approach and the Friction Cost method (FC). The $\mathrm{HC}$ approach treats humans as assets and values life and health as the change in production to the economy [14]. It values productivity loss by incorporating all income losses due to morbidity and mortality. The FC method only considers productivity loss occurring within a friction period before a replacement worker is found, plus replacement costs [15]. The two methods result in different values of productivity loss, especially for long-term disability and mortality [16-18]. When the FC method was first introduced, there was an extended discussion on which method should be used [19]. The debate is ongoing. Furthermore, the appropriateness of wage as a proxy value of marginal productivity-used to transform productivity loss into a monetary amount-has been questioned [20, 21]. As Pauly et al. [20, 21] point out, in the context of team production or tasks with high time sensitivity, if a perfect substitute for an absent worker cannot be found, the productivity loss will be greater than the worker's wage loss. Wage multipliers have been developed to adjust the wage to better represent productivity loss [21, 22]. Compensation mechanisms [18, 23, 24] are another factor influencing the value of productivity loss: workers may compensate for lost productivity at a later time, during normal or extra work hours; their colleagues may take over their work; or a temporary worker may be hired to compensate for the loss.

Research topics have been suggested to address these methodological issues $[6,13]$. The fact that NICE will take account of the wider societal benefit of drugs, including productivity impact, should be a major impetus to advance research on productivity measurement for use in economic evaluations.

Conflicts of interest Authors have no conflicts of interest to declare for the conduct of this study or for the preparation of this manuscript.

\section{References}

1. NICE. Behind the Headlines: will elderly patients miss out on new drugs? NICE. http://www.nice.org.uk/newsroom/features/ WillElderlyPatientsMissOutOnNewDrugs.jsp. Accessed 17 Jan 2014.

2. National Institute for Health and Clinical Excellence (NICE). Guide to the methods of technology appraisal. London: NICE; 2008. http://www.nice.org.uk/media/B52/A7/TAMethodsGuide UpdatedJune2008.pdf. Accessed 28 Feb 2014.

3. Claxton K, Walker S, Palmer S, Sculpher M. Appropriate perspectives for health care decisions. Centre for Health Economics, University of York; 2010. http://ideas.repec.org/p/chy/respap/ 54cherp.html. Accessed 28 Feb 2014.

4. Johannesson M, Jönsson B, Jönsson L, Kobelt G, Zethraeus N. Why should economic evaluations of medical innovations have a societal perspective?. London: Office of Health Economics; 2009.

5. UK Department of Health. The Pharmaceutical Price Regulation Scheme 2014. https://www.gov.uk/government/publications/ pharmaceutical-price-regulation-scheme-2014. Accessed 28 Jan 2014.

6. Zhang W, Bansback N, Anis AH. Measuring and valuing productivity loss due to poor health: a critical review. Soc Sci Med. 2011;72(2):185-92. doi:10.1016/j.socscimed.2010.10.026.

7. Drummond MF. Methods for the economic evaluation of health care programmes. 3rd ed. Oxford: Oxford University Press; 2005.

8. Husereau D, Drummond M, Petrou S, et al. Consolidated Health Economic Evaluation Reporting Standards (CHEERS) statement. Pharmacoeconomics. 2013;31(5):361-7. doi:10.1007/s40273013-0032-y.

9. Husereau D, Drummond M, Petrou S, et al. Consolidated Health Economic Evaluation Reporting Standards (CHEERS): explanation and elaboration: a report of the ISPOR Health Economic Evaluation Publication Guidelines Good Reporting Practices Task Force. Value Health. 2013;16(2):231-50. doi:10.1016/j.jval. 2013.02.002.

10. Beaton D, Bombardier C, Escorpizo R, et al. Measuring worker productivity: frameworks and measures. J Rheumatol. 2009; 36(9):2100-9. doi:10.3899/jrheum.090366.

11. Zhang W, Gignac MAM, Beaton D, Tang K, Anis AH. Productivity loss due to presenteeism among patients with arthritis: estimates from 4 instruments. J Rheumatol. 2010;37(9):1805-14. doi:10.3899/jrheum.100123.

12. Schultz AB, Chen C-Y, Edington DW. The cost and impact of health conditions on presenteeism to employers: a review of the literature. Pharmacoeconomics. 2009;27(5):365-78.

13. Krol M, Brouwer W, Rutten F. Productivity costs in economic evaluations: past, present, future. Pharmacoeconomics. 2013; 31(7):537-49. doi:10.1007/s40273-013-0056-3. 
14. Johannesson M. The willingness to pay for health changes, the human-capital approach and the external costs. Health Policy. 1996;36(3):231-44.

15. Koopmanschap MA, Rutten FF, van Ineveld BM, van Roijen L. The friction cost method for measuring indirect costs of disease. J Health Econ. 1995;14(2):171-89.

16. Koopmanschap M, Burdorf A, Jacob K, Meerding WJ, Brouwer W, Severens H. Measuring productivity changes in economic evaluation: setting the research agenda. Pharmacoeconomics. 2005;23(1):47-54.

17. Van den Hout WB. The value of productivity: human-capital versus friction-cost method. Ann Rheum Dis. 2010;69(Suppl 1):i89-91. doi:10.1136/ard.2009.117150.

18. Krol M, Brouwer WBF, Severens JL, Kaper J, Evers SMAA. Productivity cost calculations in health economic evaluations: correcting for compensation mechanisms and multiplier effects. Soc Sci Med. 2012;75(11):1981-8. doi:10.1016/j.socscimed. 2012.07.012.

19. Johannesson M, Karlsson G. The friction cost method: a comment. J Health Econ. 1997;16(2):249-55 (discussion 257-259).
20. Pauly MV, Nicholson S, Xu J, et al. A general model of the impact of absenteeism on employers and employees. Health Econ. 2002;11(3):221-31.

21. Pauly MV, Nicholson S, Polsky D, Berger ML, Sharda C. Valuing reductions in on-the-job illness: "presenteeism" from managerial and economic perspectives. Health Econ. 2008;17(4):469-85. doi:10.1002/hec.1266.

22. Zhang W, Bansback N, Boonen A, Severens JL, Anis AH. Development of a composite questionnaire, the valuation of lost productivity, to value productivity losses: application in rheumatoid arthritis. Value Health. 2012;15(1):46-54. doi:10.1016/j. jval.2011.07.009.

23. Severens JL, Laheij RJ, Jansen JB, Van der Lisdonk EH, Verbeek AL. Estimating the cost of lost productivity in dyspepsia. Aliment Pharmacol Ther. 1998;12(9):919-23.

24. Jacob-Tacken KHM, Koopmanschap MA, Meerding WJ, Severens JL. Correcting for compensating mechanisms related to productivity costs in economic evaluations of health care programmes. Health Econ. 2005;14(5):435-43. doi:10.1002/hec.948. 